\title{
Mortar Characteristics for Reinforcement of Ancient Tomb Murals Using Oyster Shells
}

\author{
Hwa Soo Lee | Yeong Gyeong Yu* | Kyeong Soon Han**, \\ Department of Wood and Paper Science, Chungbuk National University, Cheongju, 28644, Korea \\ *Heritage Science Center, Chungbuk National University, Cheongju, 28116, Korea \\ **Institute of Conservation of Paintings, Konkuk University, Chungju, 27278, Korea \\ ${ }^{1}$ Corresponding Author: conservation@kku.ac.kr, +82-43-840-3677
}

\begin{abstract}
The application of reinforcing agents with hydraulic property and strength development characteristics was studied under conditions similar to those of mural-painting mortar made with oyster shell powder. Reinforcement mortar made with oyster shell powder showed hydraulic properties and strength to supplement the weaknesses of natural hydraulic lime(NHL); this confirmed its possibility as a wall-reinforcing material with enough strength for preserving mural paintings. Reinforcement mortar 1 showed hydraulic property and general characteristics of lime mortar, such as consistency and viscosity, as well as lower strength and higher whiteness compared to an NHL product. For Reinforcement mortar 2 , the original wall sample characteristics were reflected by mixing more shell produced through calcination; and it showed similar strength to that of Reinforcement mortar 1 as well as high whiteness. In measuring the contraction ratio of reinforcement mortar samples, Reinforcement mortar 1 and 2 showed more stability in property change compared to the NHL Group.
\end{abstract}

Key Words: Ancient tomb mural, Natural hydraulic lime(NHL), Reinforcing agent, Oyster shell(powder), Conservation

\section{INTRODUCTION}

Studies on conservation of mural paintings in Korea began in 1986 with investigations and conservation of mural paintings in Eupnae-li, Sunheung-myeon, Korea. In recent years, various studies have been conducted on the environment, material properties, and conservation conditions of tomb mural paintings. In 2007, South-Korean conservation researchers conducted a study on the characteristics of materials used for mural paintings of Koguryo era located in Jinpa-li, North Korea(National Research Institute of Cultural Heritage and Inter-Korea Historian Association, 2007). Studies were also conducted on the conservation state and production methods on the No. 6 mural painting of the Baekje era located in Songsan-li(Han, 2011) and on the conservation state and material characteristics of mural paintings of the Gaya era located in Goa-ri(Lee et al., 2014). Although there has been much scientific research on ancient mural paintings, research on conservation techniques or materials that can cope with the damage on mural paintings is insufficient. As an example, walls were reinforced for restoring the wall paintings in Jinpa-li, North Korea, that were damaged by South Korean Conservators in 2007. At that time, however, only emergency treatment was conducted and the verification of the applied materials was insufficient.

Owing to their highly humid environmental conditions of over RH 99\%, ancient Korean mural paintings have different physical conditions than paintings above the ground, and therefore require special reinforcing materials to prevent against physical damage and humidity. Primarily, if reinforcement is required for walls with cracks or physical damages, the materials should be available for stable hardening in highly humid environment and the similarity to the original wall material and durability is necessary.

Internationally, the use of natural hydraulic lime(NHL) is increasing for mortar reinforcement for cultural properties 
in humid environments. NHL has been used as a building material since ancient times, and in recent years, NHL of various products is being widely used for restoration of ancient buildings in Japan and Europe. Regular lime mortar is made by the hardening of slaked- type lime into calcium carbonate owing to $\mathrm{CO}_{2}$ gas in the air; it is a hydraulic material that is not hardened under water. NHL is made by the calcination of low-grade limestone containing $15 \% \sim 20 \%$ of clay. Hydraulic lime contains small amounts of silicate lime $\left(3 \mathrm{CaO} \cdot \mathrm{SiO}_{2}, 2 \mathrm{CaO} \cdot \mathrm{SiO}_{2}\right)$, which is hydraulic mineral, and alumina limestone $\left(3 \mathrm{CaO} \cdot \mathrm{Al}_{2} \mathrm{O}_{3}\right)$; its hardness is similar to that of regular lime mortar and it has a hydraulic property; and improves the hardening speed and strength.

In Europe and the US, various types of NHLs have been produced, commercialized, and widely used. In addition, many international studies have been conducted on improving various characteristics of NHL made through stones in each country(Cho, 2013). For example, the study on the characterization of ancient mortar for restoration of the Ducal palace courtyard in Mantu, Italy. The analysis results of the properties and microstructure of mortar made of hydraulic lime showed that the hydraulic lime used in the study was found to be suitable for restoration of ancient buildings(Sandrolini and Franzoni, 2009).

Emergency treatment for mural paintings in Jinpa-li, North Korea(National Research Institute of Cultural Heritage and Inter-Korea Historian Association, 2007) is an example of application of NHL in Korea to cultural properties. Further, the introduction of NHL for restoration of ancient cultural properties was studied by Cho(2013), and the study focuses on examples in Europe. Han(2014) studied the characteristics of NHL to reinforce walls of tomb murals and $\mathrm{Yu}(2018)$ studied the characteristics of $\mathrm{NHL}$ as a reinforcing agent for tomb walls. According to Lee(2016), NHL has already been applied to cultural properties, historical buildings, and traditional buildings outside Korea; however, in Korea, NHL has not been considered as a conventional technique applicable to cultural properties.

According to previous studies(Lee and Ahn, 1998;
Ahn, 2003), most of the Korean mural paintings can be assumed to be made of lime mortar. However, according to the study results, the walls of some mural paintings were made using oyster shell powder and shell. The lime-plastered wall of Jinpa-li tomb No. 4 has a mixture of charcoal, clayey weathered soil, and shell in limestone (Lim, 2009). In addition, according to Lee et al.(2014), the mortar on the walls of mural paintings in Goa-ri was made of lime, formed through oysters, and contained shell pieces and lime formed through incomplete calcination; this showed low durability. In mural paintings with such low durability, reinforcement reflecting wall characteristics should be applied.

Therefore, when physical reinforcement is required for the walls of mural paintings with severe damage, hydraulic lime mortar that reflects the structure, materials, and properties of the walls could be ideal for conservation. In the current study, the authors reproduced mortar, made of oyster shell powder, with hydraulic properties reflecting the conditions of the walls of mural paintings in Goa-ri, evaluated its properties, and examined its possibility as a wall-reinforcing agent for ancient mural paintings.

\section{MATERIALS AND METHODS}

\subsection{Material selection}

In this experiment, mortars of various conditions, such as that made using oyster shell powder calcined with NHL(NHL5, St. Astier, USA), $\mathrm{CaCO}_{3}$, and oyster shell from Seomjin River, Hadong(Provided by Traditional Technique and Material Bank), were produced, and their physical properties were evaluated.

According to Lee et al.(2014), the composition of the wall mortar of the mural painting in Goa-ri does not include sand but pure $\mathrm{CaCO}_{3}$, and it contains mix of irregular shells with incomplete calcination. The shells were identified as oyster shells through an analysis, and thus, in this study, oyster shells were used for obtaining conditions similar to the original wall of the mural painting in Goa-ri. 
Table 1. Classification of samples

\begin{tabular}{|c|c|c|c|}
\hline \multicolumn{2}{|c|}{ Sample type } & \multicolumn{2}{|l|}{ Remarks } \\
\hline \multirow{4}{*}{ NHL mortar group } & \multirow{2}{*}{$100 \%$ NHL } & $50 \mathrm{~mm} \times 50 \mathrm{~mm} \times 50 \mathrm{~mm}(\mathrm{mold})$ & \multirow{10}{*}{$\begin{array}{c}25^{\circ} \mathrm{C}, 98 \% \\
\text { Curing }\end{array}$} \\
\hline & & $\varnothing 100 \times 15 \mathrm{~mm}$ (petri-dish) & \\
\hline & \multirow{2}{*}{ NHL mortar(1:2) } & $50 \mathrm{~mm} \times 50 \mathrm{~mm} \times 50 \mathrm{~mm}(\mathrm{mold})$ & \\
\hline & & $\varnothing 100 \times 15$ mm (petri-dish) & \\
\hline \multirow{2}{*}{$\begin{array}{l}\text { Reproduction of mural } \\
\text { on a tomb's wall }\end{array}$} & \multirow{2}{*}{$\begin{array}{l}\text { Representation sample } \\
\text { (Oyster shell powder) }\end{array}$} & $50 \mathrm{~mm} \times 50 \mathrm{~mm} \times 50 \mathrm{~mm}(\mathrm{mold})$ & \\
\hline & & $\varnothing 100 \times 15 \mathrm{~mm}$ (petri-dish) & \\
\hline \multirow{4}{*}{ Reinforcing agent group } & \multirow{2}{*}{$\begin{array}{l}\text { Reinforcement mortar } 1 \\
\text { (Oyster shell powder) }\end{array}$} & $50 \mathrm{~mm} \times 50 \mathrm{~mm} \times 50 \mathrm{~mm}$ (mold) & \\
\hline & & $\varnothing 100 \times 15 \mathrm{~mm}$ (petri-dish) & \\
\hline & \multirow{2}{*}{$\begin{array}{c}\text { Reinforcement mortar } 2 \\
\text { (Oyster shell powder) }\end{array}$} & $50 \mathrm{~mm} \times 50 \mathrm{~mm} \times 50 \mathrm{~mm}(\mathrm{mold})$ & \\
\hline & & $\varnothing 100 \times 15 \mathrm{~mm}$ (petri-dish) & \\
\hline
\end{tabular}

\subsection{Study method}

To identify the characteristics of the reinforcing agent for the walls of mural paintings, various types of mortar samples were produced, and their properties were compared. First, lime, the main material for the walls, and NHL, which is used for wall reinforcement, were compared in terms of hardening speed. To evaluate their applicability as a reinforcing agent for the mural-painted walls, samples were produced according to mortar conditions of NHL and hydraulic reinforcing mortar using oyster shell powder to evaluate their hardening characteristics, and comparative analysis was conducted for various properties.

\subsubsection{Evaluating material characteristics}

To analyze mortar-hardening characteristics in highly humid conditions, a modified vicat apparatus(ASTM C807, Mesys, Colombia) was used on mortar produced through NHL and slaked lime(KS L 5108). In addition, to identify characteristics on measurement stability, a Ø100 $\times 15 \mathrm{~mm}$ petri-dish was used for making samples of NHL mortar[NHL(1):Sand(2)] for observation.

\subsubsection{Samples development}

\subsubsection{Development of oyster shells and oyster shell powder}

A representation sample, which is similar to the walls with ancient mural paintings, was developed based on an existing study result(Lee et al., 2014). Completely cleansed river oysters was calcined in an electric furnace(KK80,
Elim Global, Korea) at 650,750 , and $850^{\circ} \mathrm{C}$ for $24 \mathrm{~h}$. The calcined oyster shells were crushed in a pestle bowl and divided according to grain sizes: over $4.0 \mathrm{~mm}, 4.0-1.0$ $\mathrm{mm}, 1.0-0.5 \mathrm{~mm}, 0.5-0.2 \mathrm{~mm}$, and below $0.2 \mathrm{~mm}$.

\subsubsection{Evaluation of the hydraulic hardening property}

To select a reinforcing agent that can be used in the temperature and humidity conditions of mural paintings, conditional samples were produced and preserved in a desiccator(temperature of $25^{\circ} \mathrm{C}$ and relative humidity of $98 \%$ ) before evaluating its hardening property. The sample contained calcined oyster shell powder as the basic material, shells treated with incomplete calcination, natural silica powder $\left(\mathrm{SiO}_{2}\right)$, white clay(Kaolinite, white clay from Hapcheon-gun), and $\mathrm{CaCO}_{3}$. The sample's hardening property was evaluated through naked-eye observations, and physical change and chromaticity were observed; the reinforcing agent criteria were established by selecting the best hardening result.

\subsubsection{Development of mortar sample}

Mortar samples in all the conditions were filled in a $50 \mathrm{~mm} \times 50 \mathrm{~mm} \times 50 \mathrm{~mm}$ molds and $\varnothing 100 \times 15 \mathrm{~mm}$ petridish, preserved in $98 \%$ humidity at $2{ }^{\circ} \mathrm{C}$, and removed after 1 day. The mold sample was produced for testing compressive strength and the petri-dish sample was produced for other experimentations(Table 1).

The NHL mortar Group was composed of mortar mixed with distilled water and NHL only, where the 
Table 2. Mortar samples in all conditions

\begin{tabular}{|c|c|c|c|}
\hline \multirow{2}{*}{ Sample type } & \multicolumn{2}{|c|}{$50 \mathrm{~mm} \times 50 \mathrm{~mm} \times 50 \mathrm{~mm}($ mold $)$} & $\varnothing 100 \times 15 \mathrm{~mm}$ (petri-dish) \\
\hline & Day 7 & Day 28 & Day 28 \\
\hline $100 \%$ NHL & & & \\
\hline NHL mortar(1:2) & & & \\
\hline $\begin{array}{l}\text { Representation } \\
\text { sample }\end{array}$ & & & \\
\hline $\begin{array}{l}\text { Reinforcement } \\
\text { sample } 1\end{array}$ & & & \\
\hline $\begin{array}{l}\text { Reinforcement } \\
\text { sample } 2\end{array}$ & & & \\
\hline
\end{tabular}

mortar was made of NHL and sand in a $1: 2$ ratio. In the reproduction of the tomb's wall comprising the mural paintings, the mixing ratio of the mural-painting representation sample was based on the grain-size analysis by Konkuk University(2013). Then, the oyster shells and oyster shell powder were mixed in a $1: 1$ ratio. To develop the oyster shell powder, a shell was crushed in a pestle bowl and mixed with $\mathrm{CaCO}_{3}$. After comparing the hardening properties, the sample of the reinforcing agent group was produced according to the proper conditions for reinforcing agents. For reinforcement mortar 1, the oyster shell powder $(\mathrm{CaO})$ was mixed with $\mathrm{CaCO}_{3}$ and natural silica powder $\left(\mathrm{SiO}_{2}\right)$; sand was mixed with plaster in a $2: 1$ ratio. For reinforcement mortar condition 2, the oyster shell powder $(\mathrm{CaO})$ was mixed with $\mathrm{CaCO}_{3}$ and natural silica powder $\left(\mathrm{SiO}_{2}\right)$, and oyster shell powder and shell were added to this mixture; moreover, plaster, shell, and sand were mixed in a $1: 0.5: 1.5$ ratio(Table 2).

\subsubsection{Property evaluation}

A machine(AGS-100NJ Table-top type, Shimadzu, Japan) was used to measure the compressive strength according to the material age based on KS L 5105. The first measurement was performed after seven days after production, and the second measurement was performed on day 28 according to the material age of regular lime. Strength measurement was conducted at $10 \mathrm{~mm} / 10 \mathrm{~min}$, and the average value from three samples was used to obtain the compressive strength. The conditional mortar chromaticity was measured using a spectrum colorimeter (Color mate, Sinco, Korea) with a 3-point sample average. The whiteness of each sample during curing was compared and the chrominance values were compared according to the representation sample. The conditional mortar contraction ratio was measured using digital Vernier calipers; each sample's length was measured at $0^{\circ}$, $120^{\circ}$, and $240^{\circ}$, and their average value was calculated. The contraction ratio difference was confirmed through the average value. The conditional mortar absorption ratio was measured according to $\mathrm{KS} F$ 2518, and the sample was dried in a drying furnace for $24 \mathrm{~h}$ at $105 \pm 3^{\circ} \mathrm{C}$ and cooled indoors for $30 \mathrm{~min}$ before measuring the weight (A). The sample was then sunk in distilled water for $48 \mathrm{~h}$; the moisture on the surface was wiped off, and the weight (B) was measured with the precision of $0.01 \mathrm{~g}$. 


\section{RESULTS}

\subsection{Evaluation of material characteristics}

According to the evaluation of the hydraulic hardening characteristics, the slaked lime did not initially set, and the final setting even after 2 months. In contrast, NHL initially set after $24 \mathrm{~h}$ and hardened completely after approximately $48 \mathrm{~h}$. According to the dimensional stability test, the slaked lime mortar showed significant cracks and contractions, whereas the NHL mortar showed no measurement

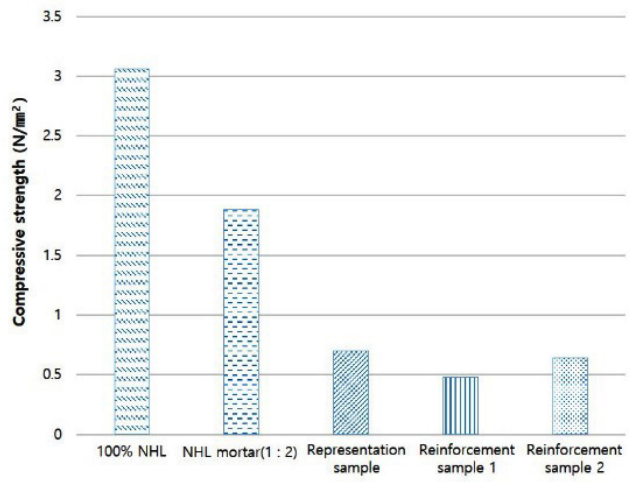

Figure 1. Compressive strength of sample on day 7. change. According to material characteristic evaluation, the NHL mortar is considered to be suitable as a reinforcing agent mural-painted walls in terms of dimensional stability and hardening speed.

\subsection{Evaluation of properties}

\subsubsection{Compressive strength}

According to the compressive strength test, the strengthincrease trends were similar between day 7 and day 28; however, $100 \%$ NHL showed a higher compressive

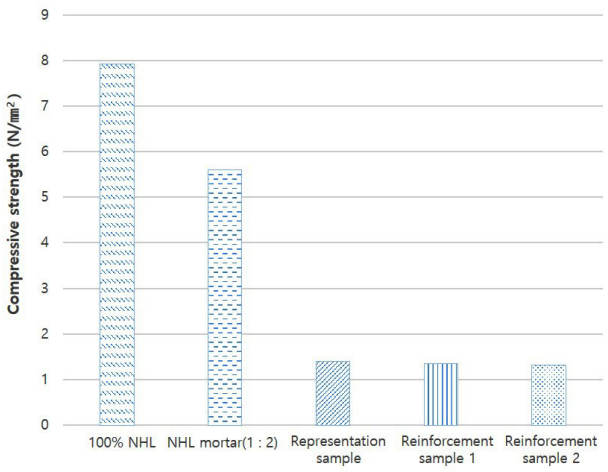

Figure 2. Compressive strength of sample on day 28.

Table 3. Compressive strengths of samples

\begin{tabular}{|c|c|c|c|c|c|}
\hline \multicolumn{3}{|c|}{ Day 7} & \multicolumn{3}{|c|}{ Day 28} \\
\hline Sample type & Measure $\left(\mathrm{N} / \mathrm{mm}^{2}\right)$ & Average $\left(\mathrm{N} / \mathrm{mm}^{2}\right)$ & Sample type & Measure $\left(\mathrm{N} / \mathrm{mm}^{2}\right)$ & Average $\left(\mathrm{N} / \mathrm{mm}^{2}\right)$ \\
\hline \multirow{3}{*}{$100 \%$ NHL } & 3.02 & \multirow{3}{*}{3.06} & \multirow{3}{*}{$100 \%$ NHL } & 7.66 & \multirow{3}{*}{7.92} \\
\hline & 3.09 & & & 7.70 & \\
\hline & 3.08 & & & 8.40 & \\
\hline \multirow{3}{*}{$\begin{array}{l}\text { NHL mortar } \\
\quad(1: 2)\end{array}$} & 2.56 & \multirow{3}{*}{2.51} & \multirow{3}{*}{$\begin{array}{l}\text { NHL mortar } \\
\quad(1: 2)\end{array}$} & 5.28 & \multirow{3}{*}{5.60} \\
\hline & 2.43 & & & 5.49 & \\
\hline & 2.54 & & & 6.03 & \\
\hline \multirow{3}{*}{$\begin{array}{l}\text { Representation } \\
\text { sample }\end{array}$} & 0.72 & \multirow{3}{*}{0.70} & \multirow{3}{*}{$\begin{array}{l}\text { Representation } \\
\text { sample }\end{array}$} & 0.92 & \multirow{3}{*}{0.90} \\
\hline & 0.69 & & & 0.87 & \\
\hline & 0.79 & & & 0.90 & \\
\hline \multirow{3}{*}{$\begin{array}{l}\text { Reinforcement } \\
\text { sample } 1\end{array}$} & 0.50 & \multirow{3}{*}{0.48} & \multirow{3}{*}{$\begin{array}{l}\text { Reinforcement } \\
\text { sample } 1\end{array}$} & 1.56 & \multirow{3}{*}{1.35} \\
\hline & 0.47 & & & 1.16 & \\
\hline & 0.45 & & & 1.33 & \\
\hline \multirow{3}{*}{$\begin{array}{l}\text { Reinforcement } \\
\text { sample } 2\end{array}$} & 0.63 & \multirow{3}{*}{0.64} & \multirow{3}{*}{$\begin{array}{l}\text { Reinforcement } \\
\text { sample } 2\end{array}$} & 1.27 & \multirow{3}{*}{1.31} \\
\hline & 0.68 & & & 1.36 & \\
\hline & 0.63 & & & 1.30 & \\
\hline
\end{tabular}


Table 4. Chromaticity of sample type(days 7 and 28)

\begin{tabular}{ccccccccc}
\hline \multirow{2}{*}{ Sample type } & \multicolumn{4}{c}{ Day 7} & \multicolumn{4}{c}{ Day 28 } \\
\hline 100\% NHL & $L^{*}$ & $a^{*}$ & $b^{*}$ & $\Delta E$ & $L^{*}$ & $a^{*}$ & $b^{*}$ & $\Delta E$ \\
\hline NHL mortar(1 : 2) & 77.53 & 0.03 & 6.13 & 7.88 & 82.23 & 0.17 & 6.69 & 8.85 \\
\hline Representation sample & 79.78 & -0.12 & 4.65 & 8.70 & 83.28 & 0.08 & 5.54 & 7.32 \\
\hline Reinforcement sample 1 & 79.76 & 0.74 & 5.00 & 8.91 & 87.78 & 0.13 & 2.25 & 1.75 \\
\hline Reinforcement sample 2 & 69.07 & 0.06 & 2.39 & 3.83 & 81.83 & -0.14 & 1.28 & 6.24 \\
\hline
\end{tabular}

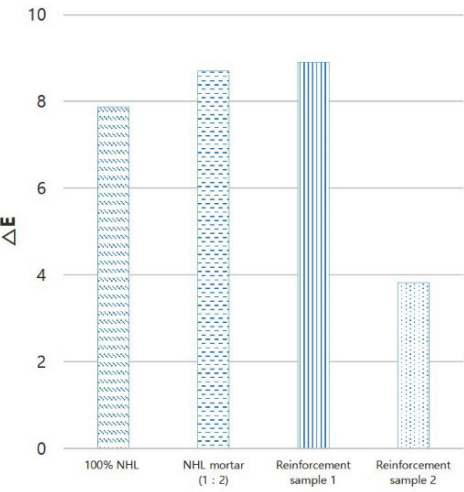

Figure 3. Comparison of Goa-ri representation sample on day 7 .

strength value on days 7 and 28 compared with those of other samples, followed by NHL mortar. The representation sample of mural-painted wall showed significantly lower value compared with those of $100 \%$ NHL and NHL mortar; and was measured as 0.7 and $0.9 \mathrm{~N} / \mathrm{mm}^{2}$ on days 7 and 28, respectively. Reinforcement mortars 1 and 2 showed similar values to that of the representation sample; on day 7 , reinforcement mortar 2 showed higher strength than reinforcement mortar 1, whereas reinforcement mortar 1 showed a slightly higher value on day 28(Table 3, Figures 1, 2).

\subsubsection{Chromaticity}

On day 7 of curing, the color difference among $100 \%$ NHL, NHL mortar, and reinforcement sample 1 was great and the values of reinforcement sample 2 were the lowest, indicating closest chromaticity(Table 4, Figure 3). For color difference on day 28 of curing, 100\% NHL showed the highest value and reinforcement sample 1 showed the

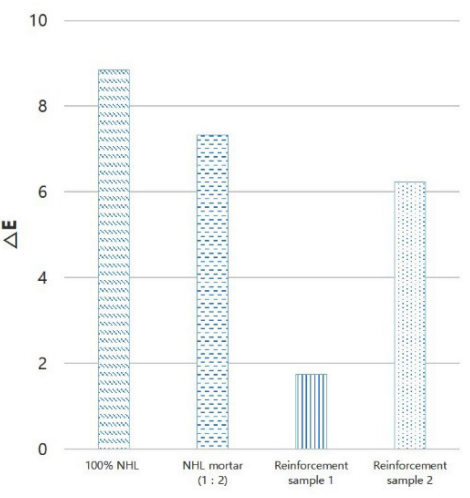

Figure 4. Comparison of Goa-ri representation sample on day 28 .

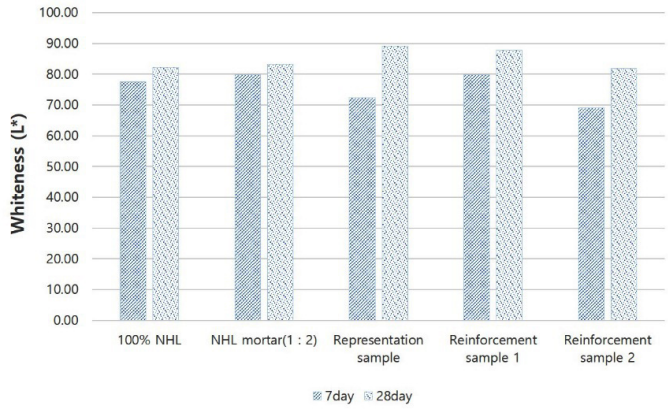

Figure 5. Whiteness of sample type(days 7 and 28).

lowest value. The sample with $100 \%$ NHL showed lower $L^{*}$ value than the representation sample, while its $a^{*}$ and $b^{*}$ values were higher. On day 28 of curing, reinforcement sample 1 showed the closest chromaticity to that of the representation sample(Table 4, Figure 4). The comparison of whiteness according to hardening time showed that the oyster shell-applied sample showed higher increase in whiteness, than the NHL-applied sample. On day 7 of 
curing, the NHL-applied sample showed more whiteness, whereas on day 28, the shell-applied sample showed more whiteness. Although the representation sample showed the lowest whiteness on day 7 , it showed the highest whiteness on day 28(Table 4, Figure 5).

\subsubsection{Contraction ratio}

In the measurement of length of each conditional sample on day 28 of curing, the contraction ratios of all samples were below $1 \%$, while the $100 \%$ NHL, not mixed with an aggregate, showed the highest ratio of $0.51 \%$. Reinforcement sample 2 showed the lowest ratio of $0.08 \%$, which is six times lower than that of $100 \%$ NHL.

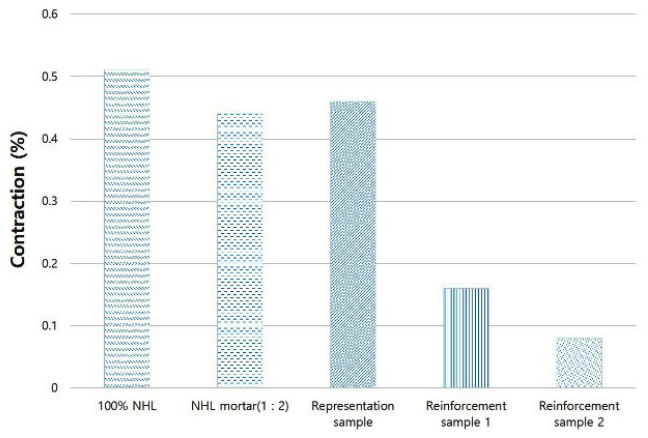

Figure 6. Contraction of different samples.
NHL mortar showed $0.44 \%$ contraction ratio and reinforcement sample 1 showed a relatively low ratio of $0.16 \%$ (Table 5 , Figure 6).

\subsubsection{Absorption ratio}

The $100 \%$ NHL and representation samples showed relatively high ratio of over $30 \%$, and reinforcement sample 1 showed the lowest ratio of $14.75 \%$ (Table 6 , Figure 7 ).

\section{DISCUSSION}

To identify the hardening characteristics of NHL and hydraulic material, a test was conducted using a Vicat

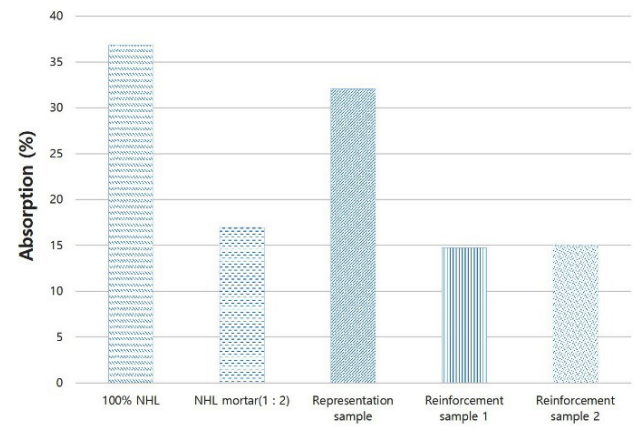

Figure 7. Absorption of sample type.

Table 5. Contraction of sample type (\%)

\begin{tabular}{ccccc}
\hline Contraction & 1st & 2nd & 3rd & Average \\
\hline $100 \%$ NHL & 0.53 & 0.67 & 0.34 & 0.51 \\
\hline NHL mortar(1 : 2) & 0.42 & 0.41 & 0.50 & 0.44 \\
\hline Representation sample & 0.58 & 0.43 & 0.37 & 0.46 \\
\hline Reinforcement sample 1 & 0.19 & 0.10 & 0.19 & 0.16 \\
\hline Reinforcement sample 2 & 0 & 0.15 & 0.08 & 0.08 \\
\hline
\end{tabular}

Table 6. Absorption of sample type (\%)

\begin{tabular}{ccccc}
\hline Sample type & 1st & 2nd & 3rd & Average \\
\hline $100 \%$ NHL & 37.29 & 36.35 & 37.12 & 36.82 \\
\hline NHL mortar(1 : 2) & 16.49 & 17.41 & 16.35 & 16.95 \\
\hline Representation sample & 32.58 & 31.55 & 31.45 & 32.07 \\
\hline Reinforcement sample 1 & 14.82 & 14.68 & 13.56 & 14.75 \\
\hline Reinforcement sample 2 & 15.01 & 15.04 & 15.10 & 15.03 \\
\hline
\end{tabular}


needle apparatus. The hardening time of NHL was confirmed to be approximately $48 \mathrm{~h}$. The next test was conducted on the conditional sample that can be used as the reinforcing agent of the mural-painted wall in a highly humid environment. Most conditions were not suitable owing to low strength as well as slow hydration reaction; however, samples with $\mathrm{CaCO}_{3}$ and natural silica powder as well as $\mathrm{CaO}$ showed higher durability than other samples.

After comparing the hardening characteristics, two conditions suitable for the reinforcing agent of a muralpainted wall were selected for production. All the conditional samples showed an increase in the compressive strength with the curing time. Compared to the strength of the representation sample, those of $100 \%$ NHL and NHL mortar were 2-4 times higher. As the strength was extremely greater than that of the original wall, it can cause damage to the material of the original wall because of the stress difference in the wall. Therefore, $100 \%$ NHL and NHL mortar were considered not suitable as reinforcing agents in terms of strength. In contrast, the strengths of reinforcement mortar 1 and 2 showed no significant difference from that of the representation sample. This may indicate that these three samples with oyster shell powder mortar have conditions similar to that of the mortar component of the mural-painted wall in Goa-ri.

According to the chromaticity measurement, the conditions of reinforcement mortar 1 and 2 showed the most similar chromaticity to that of the representation sample on days 7 and 28 of curing. After day 28, reinforcement mortar 1 showed high similarity with the lowest chromaticity value. Second, reinforcement mortar 2 was similar to the representation sample. The overall whiteness during the curing period increased with time and hardening progress. The oyster shell powder-added samples showed more increase in whiteness on day 28 than on day 7 .

According to the measurement of contraction ratio, the ratios of all samples were below $1 \%$, and those of reinforcement mortar 1 and 2 were lowest. The $100 \%$ NHL sample showed higher ratio than that of NHL mortar, indicating that it depends on the mixing of the aggregate. Reinforcement mortar 1 and 2 showed almost no change of dimensional stability owing to the presence of $\mathrm{CaCO}_{3}$ and the roles of oyster shell powder and shells with various grain sizes.

According to the absorption-ratio measurement, 100\% NHL showed the highest ratio of approximately 36\%, whereas reinforcement mortar 1 showed the lowest ratio of approximately $14 \%$. The absorption ratio of the representation sample was as high as $32 \%$ and those of NHL mortar and reinforcement mortar 1 and 2 were over 14\%, indicating lower values than that of the representation sample but better absorption than that of cement.

\section{CONCLUSION}

A reinforcing agent reflecting the material characteristics of mural-painted walls made of shells was produced and its applicability was tested. The result confirmed that the hydraulicity and strength were identified even when an NHL product was not used. Reinforcement mortar 1 showed hydraulicity, less strength, and more whiteness than samples with NHL product. For reinforcement mortar 2, high content of shell was mixed to reflect characteristics of the original wall sample, and its strength was similar to that of reinforcement mortar 1 with high whiteness level.

According to the contraction ratio measurement on the reinforcing samples, reinforcement mortar 1 and 2 showed more stability in the property change level compared to the NHL product group. In addition, according to the absorption test, the NHL product group showed high level of absorption, indicating that reinforcement mortar 1 and 2 are relatively stable. Compared to the representation sample, reinforcement mortar 1 and 2 mixed with calcined shells showed physical characteristics including similar strength, relatively low level of absorption, and contraction ratio. Therefore, it would be a suitable reinforcing agent for mural-painted walls made of shell compared to NHLapplied samples, which show approximately 4-6 times different strength.

If a pilot test is conducted reflecting the interior condition of tombs according to the reinforcing agent condition 
confirmed by this study, the property evaluation of the reinforcing agent can be more objectively identified for stable application.

\section{ACKNOWLEDGEMENT}

This study was conducted as part of the "Planning of closure and conservation for mural painting of Goa-ri tomb in Goryeong, Gaya in 2017," supported by the Goryeong-Gun and Cultural Heritage Administration

\section{REFERENCES}

Ahn, B.C., 2003, Study on the technique of making ground walls for wall-paintings of Koguryo tombs. Study of Koguryo, 16. (in Korean with English abstract)

Cho, J.S., 2013, Physical and chemical properties of natural hydraulic lime-based pastes and mortars. Docter's thesis, Kangwon University, Chuncheon, 1-224. (in Korean with English abstract)

Han, K.S., 2011, Making technique studies of mural paintings in the No. 6 Tomb of Songsanri, Gongju. Journal of Conservation Science, 27(4), 451-458. (in Korean with English abstract)

Han, K.S., 2014, A study for the conservation of ancient mural in Korea : Natual hydronic lime mortar for the treatment of Goguryeo Murals. Mural paintings forum of shaanxi History Museum, Shaanxi, October 16-17, 121-125.

Konkuk University, 2013, Study on the conservation for mural painting of Goa-ri tomb in Goryeong, Gaya. 1-274. (in Korean)
Lee, H.S., Lee, H.H., Lee, K.M. and Han, K.S., 2014, Study on the manufacturing technology of mural tomb in Goa-dong of Daegaya period. Journal of Conservation Science, 30(4), 457-466. (in Korean with English abstract)

Lee, S.O., 2016, Manufacturing techniques of traditional lime mortars in Joseon dynasty. Master's thesis, Korea National University of Cultural Heritage, Buyeo, 1-17. (in Korean with English abstract)

Lee, S.S. and Ahn, B.C., 1998, A preliminary thought on production technics of mural paintings Goguryeo. Study of Goguryeo, 5, 195-215. (in Korean with English abstract)

Lim, K.W., 2009, Study on properties of lime plaster at mural in Goguryo Tomb : A case study on Jinpari Tomb No.4. Journal of Northeast Asian History, 23, 205-237. (in Korean with English abstract)

National Research Institute of Cultural Heritage and inter-Korea Historian Association, 2007, Report on conservation research of murals in Goguryeo Tombs No.1. (in Korean with English abstract)

Sandrolini, F. and Franzoni, E., 2009, Characterization procedure for ancient mortars' restoration: The plasters of the Cavallerizza courtyard in the Ducal Palace in Mantua (Italy). International Metallographic Society, 61(1), 97-104.

Yu, Y.G., 2018, Study on applicability to NHL(natural hydraulic lime) for reinforcement of mural painting in ancient tomb. Bachelor's thesis, Korea National University of Cultural Heritage, Buyeo, 1-16. (in Korean with English abstract) 